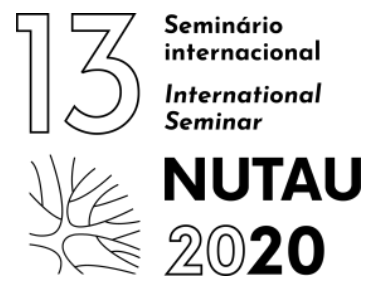

\title{
Sensoriamento remoto e geoprocessamento aplicados ao mapeamento da arborização urbana na cidade do Rio de Janeiro
}

\author{
Bruno Ragi Eis Mendonça ${ }^{1}$, Fabiana Simões dos Santos ${ }^{2}$, Vera Regina Tângari ${ }^{3}$ \\ ${ }^{1}$ Mestre em Arquitetura PROARQ-UFRJ, brunoragiarq@gmail.com \\ 2 Graduanda, Universidade Federal do Rio de Janeiro - FAU-UFRJ, simoes.fabs@gmail.com \\ 3 Professora Associada, Universidade Federal do Rio de Janeiro - FAU-UFRJ, vtangari@gmail.com
}

\begin{abstract}
RESUMO: Em face ao desafio da acelerada urbanização, o papel desempenhado pela arborização na configuração dos espaços urbanos é sem dúvida ponto de grande importância. A arborização é elemento de destaque na configuração do tecido urbano da Cidade do Rio de Janeiro, proporcionando a seus habitantes benefícios ambientais, estéticos, sociais e econômicos. Nesse contexto, os objetivos principais desse trabalho incluíram: identificar, categorizar e quantificar a arborização urbana, buscando dessa maneira compreender a distribuição desse elemento nas diferentes regiões da Cidade. A partir da utilização de métodos de sensoriamento remoto e geoprocessamento, a pesquisa buscou correlacionar dados de incidência da arborização nos espaços livres de edificação, públicos e privados em área específica da Cidade: a Área de Planejamento 1 (AP1). Os resultados destacam, por exemplo, o predomínio da arborização incidente em espaços livres privados, representando mais de $70 \%$ de toda a massa arbórea identificada na AP1, evidenciando, portanto, a importância da manutenção de tais espaços em determinadas regiões. Em climas com características de temperatura e umidade como os da Cidade do Rio de Janeiro a incidência de arborização se constitui em demanda de conforto e bem estar, justificando a ampliação de estudos como os demonstrados nesse artigo para outras regiões da cidade.
\end{abstract}

PALAVRAS-CHAVE: Arborização Urbana, espaços livres de edificação, sensoriamento remoto, Rio de Janeiro.

ABSTRACT: Given the challenge of accelerated urbanization, the role played by afforestation in the configuration of urban spaces is undoubtedly a point of great importance. Afforestation is a prominent element in the configuration of the urban fabric of the City of Rio de Janeiro, providing its inhabitants with environmental, aesthetic, social, and economic benefits. In this context, the main objectives of this paper include: to identify, categorize, and quantify urban afforestation, thus seeking to understand the distribution of this element in the different regions of the City. Based on remote sensing and geoprocessing methods, the research sought to correlate data on the incidence of afforestation in open public and private spaces in a specific area: Planning Area 1 (AP1). The results highlight, for example, the predominance of afforestation in private open spaces, representing more than $70 \%$ of the entire afforestation identified in AP1, thus evidencing the importance of such spaces in certain regions. In climates with temperature and humidity characteristics such as those of the City of Rio de Janeiro the incidence of afforestation constitutes a demand for comfort and well-being, justifying the expansion of studies to other regions of the city.

KEYWORDS: Urban Afforestation, open spaces, remote sensing, Rio de Janeiro.

\section{INTRODUÇÃO}

Em face ao desafio da acelerada urbanização, o papel desempenhado pela arborização na configuração dos espaços urbanos é sem dúvida um ponto de grande importância. $\quad \mathrm{Na}$ ausência de adequado planejamento, o crescimento do tecido urbano altera de forma significativa o ambiente, provocando mudanças nas características climáticas locais assim como contrastes entre ambientes edificados e não edificados. Nesse cenário, a arborização tem um destaque especial no tocante à qualidade de vida, proporcionando às cidades e seus habitantes benefícios ambientais, estéticos, sociais e econômicos.

A verdadeira função do elemento arbóreo vai muito além das questões estéticas originadas no século XVII, ou das políticas higienistas do século XIX. Diversos autores atestam a importância do elemento vegetal em meio urbano, em seu caráter geo-biofísico, cultural e ambiental (BARRA et al., 2015). A partir de meados do século XIX a importância da presença da arborização nas cidades passou a ser destacada por vários profissionais e teóricos do urbanismo e paisagismo, como Sitte (1900 apud COLLINS, G; COLLINS, Christiane C, 2006), Lynch (1972) e Cullen (1999). Esses autores buscaram retratar não apenas os benefícios estéticos da arborização, mas também questões simbólicas, psicológicas e emocionais relacionadas às contribuições do elemento vegetal na 
paisagem urbana. Nesse contexto, observando-se principalmente as questões climáticas e geo-biofísicas da Cidade do Rio de Janeiro, o elemento vegetal ganha destaque, juntamente com demais elementos morfológicos do espaço urbano, principalmente os espaços livres de edificação (MAGNOLI, 2006a e 2006b).

\section{ESPAÇOS LIVRES E ARBORIZAÇÃO URBANA}

Nas duas últimas décadas, grandes transformações, territoriais e sociais, vêm ocorrendo na Cidade do Rio de Janeiro. Muitas dessas mudanças ocorreram em consequência da realização de megaeventos culturais e esportivos sediados na íntegra, ou parcialmente, na Cidade. São exemplos, os Jogos Pan-americanos em 2007, a Jornada Mundial da Juventude em 2013, a Copa do Mundo de Futebol em 2014 e os Jogos Olímpicos em 2016. Significativas reformulações urbanísticas e arquitetônicas foram responsáveis por transformar a paisagem da Cidade, sem, contudo, levar em consideração de forma sistemática às consequências de tais transformações, os anseios da população, e, sobretudo, as reais necessidades de determinadas regiões da Cidade. Dessa forma, o espaço livre urbano vem sendo prioritariamente relegado ao tratamento de questões ligadas à circulação de veículos e pedestres, comprometendo o caráter social e ambiental desse espaço, desenvolvendo dessa maneira, uma paisagem desprovida de identidade (SILVA, 2004 apud TANGARI et al. 2009, p. 21) (Fig.1).

Os espaços livres (EL) urbanos se destacam na paisagem da cidade e possuem extrema relação com a qualidade de vida e com a dinâmica de ocupação do território. Segundo Tângari, "ao se formar através da ação de agentes públicos e privados, a cidade conjuga espaços construídos e espaços livres de edificação [...] tanto os espaços construídos quanto os livres de edificação conferem caráter e qualificam a paisagem das cidades" (TANGARI, 1999, p.184). Outros autores complementam a conceituação dos espaços livres como sistemas, ressaltando seu caráter de conectividade e complementaridade mesmo que não tenham sido pensados como tal. (QUEIROGA \& BENFATTI, 2007).

Da mesma forma, os benefícios ecológico-ambientais que a arborização proporciona aos centros urbanos são diversos, e a sua participação na organização da paisagem e na definição dos espaços não edificados é uma contribuição de grande importância e que merece o seu devido destaque (FARAH, 1997).

Nesse contexto, esse trabalho objetiva identificar, categorizar e quantificar a arborização existente na Cidade do Rio de Janeiro, buscando não apenas compreender a incidência e distribuição desse elemento nos diferentes espaços livres da Cidade, como também ser material complementar de referência para estudos e projetos que tratem da arborização pública e privada na Cidade do Rio de Janeiro.

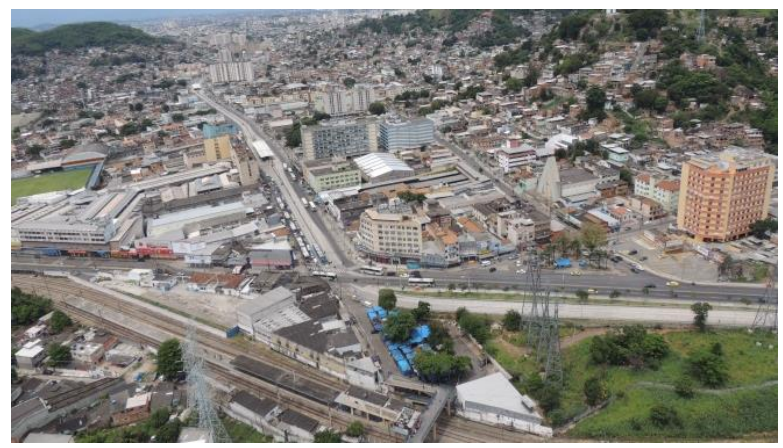

Figura 1: Impacto na paisagem de trecho de bairro na Zona Norte da Cidade no Rio de Janeiro, após obras viárias de grande porte.

Fonte: Grupo SEL-RJ, 2017.

\section{3. ÁREA DE ESTUDO E METODOLOGIA}

Como compartimentos espaciais de análise a pesquisa toma como base os limites das Áreas de Planejamento (APs) e das Regiões Administrativas (RAs) da cidade do Rio de Janeiro (Fig. 2). Essas áreas foram definidas no primeiro Plano Diretor da Cidade, criado através da Lei Complementar no 16 de 1992, chamado de Plano Diretor Decenal. Segundo o plano, a divisão administrativa da Cidade não se daria mais por simples zonas (urbana, suburbana e rural ou em residenciais, industriais, comerciais e turísticas), mas sim em cinco grandes áreas, chamadas de Áreas de Planejamento (AP). Para cada uma delas, foram traçadas metas distintas de crescimento e desenvolvimento urbano, através do controle da expansão urbana em determinadas áreas ou do incentivo a essa expansão, em outras. Além das áreas de planejamento, foram ainda estabelecidas, dentro de cada AP, subáreas denominadas Regiões Administrativas (RA), que são agrupamentos de bairros vizinhos, definidos por suas semelhanças, em relação a características morfológicas e socioambientais.

O artigo busca apresentar os dados e resultados obtidos no mapeamento de uma das cinco Áreas de Planejamento que conformam a Cidade: a Área de Planejamento 1 (AP1). 


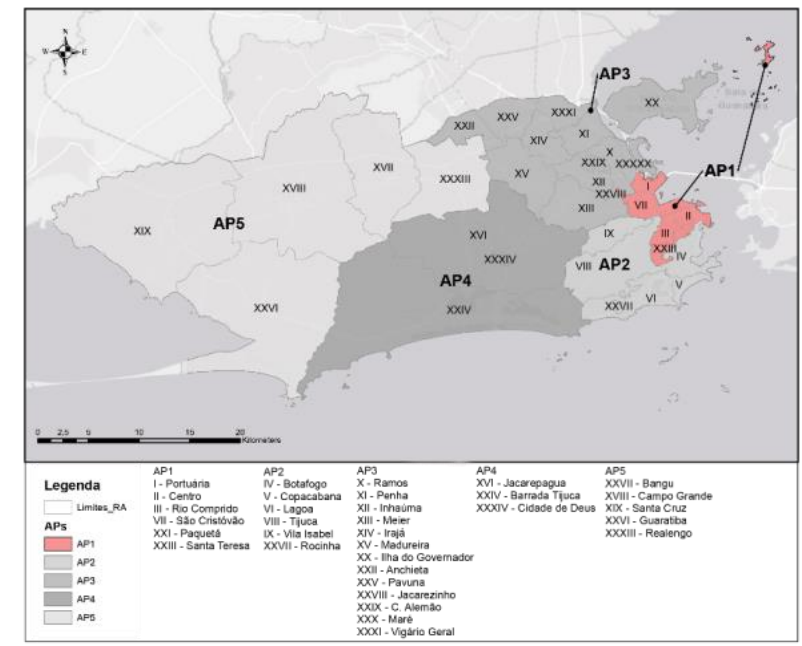

Figura 2: Divisão administrativa da Cidade do Rio de Janeiro. Destaque para a AP1.

Fonte: DATARIO, 2020. Mapa adaptado pelos autores.

A AP1 configura-se como a área mais a leste da Cidade do Rio de Janeiro, e que representa a região do centro-administrativo da Cidade. Formada por seis Regiões Administrativas (Portuária - RA I, Centro - RA II, Rio Comprido - RA III, São Cristóvão - RA VII, Paquetá - RA XXI e Santa Teresa - RA XXIII), a AP1 é a menor área em extensão territorial - cerca de $8 \%$ da área total da Cidade - e ainda apresenta o menor percentual de domicílios e população por Área de Planejamento (Fig. 3).

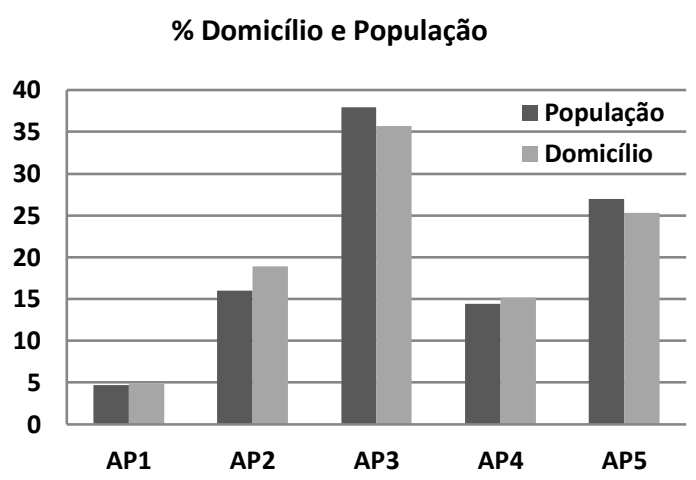

Figura 3: Percentual de domicílios e população por Área de Planejamento.

Fonte: IBGE, 2011.

O mapeamento da arborização foi realizado a partir da vetorização manual de polígonos, a partir de base de imagens satélite georreferenciadas (ortofotos) da Cidade do Rio de Janeiro, do ano de 2015 - fornecidas pelo Instituto Pereira Passos (IPP/PCRJ) - utilizando-se software de geoprocessamento (ArcGISv.10.6.1/ESRIC).

Nesse processo de conversão de imagens tipo raster (ortofotos) em arquivos vetoriais por meio da digitalização sobre a imagem apresentada na tela do computador, a escala pré-determinada para a detecção dos polígonos que representam a massa arborizada foi de 1:2000.

Um segundo método possível de vetorização dos polígonos de arborização seria o uso imagens satélites georreferenciadas com banda de cores vermelha e infravermelha. Nesse caso, a partir da utilização de ferramentas de análises espaciais disponíveis no software de geoprocessamento (ArcGIS/ESRIC) é possível a determinação do Índice de Vegetação da Diferença Normalizada (Normalized Difference Vegetation Index - NDVI), a partir da detecção da intensidade de atividade clorofiliana.

Espécies vegetais absorvem elevada quantidade de radiação infravermelha (entre 400 e 700 nanômetros) para realização da fotossíntese, desta maneira, sua identificação automática torna-se possível através desse procedimento (CRUZ, 2013).

Embora seja possível a otimização do processo de identificação de áreas vegetadas em grandes extensões territoriais, tendo em vista o enorme ganho de tempo no processo de mapeamento dessas áreas, há de se considerar a dificuldade em se diferenciar, com a utilização desse método, áreas de forração de espécies arbóreas e arbustivas, o que implica diretamente na falta de acurácia dos valores finais medidos da massa ou fragmentos arbóreos.

Por conta dessa limitação, essa pesquisa optou pelo processo de vetorização manual por entender que a precisão e o grau de confiabilidade dos dados gerados seriam superiores ao método dinamizado que leva em consideração o NDVI.

Para efeitos de mapeamento, foi previamente estabelecido que as massas arbóreas incidentes sobre Unidades de Conservação, mais precisamente as Áreas de Proteção Integral (municipais, estaduais e federais), seriam desconsideradas nessa pesquisa. É o caso, por exemplo, do Parque Nacional da Tijuca. Isso se deve ao fato de que a inclusão dessas áreas poderia alterar de maneira significativa os resultados pretendidos nessa pesquisa, onde se busca analisar a distribuição da arborização urbana, em espaços de uso cotidiano da população, onde não se aplicam regras e diretrizes de proteção ambiental. Foi ainda estabelecido que a mínima área relevante a ser vetorizada fosse de $28 \mathrm{~m}^{2}$, que nesse caso representaria a área de copa de uma espécie arbórea de médio porte. ${ }^{1}$

Já para a definição das classes de análise da arborização previamente mapeada, o estudo levou

1 Quadro síntese de valores referenciais de porte arbóreo: (http://www.campinas.sp.gov.br/governo/seplama/luos/porte_de arvores.pdf). Acessado em 30/10/2020. 
em consideração pesquisa anterior (TÂNGARI, 2018, 2019), que teve como objetivo principal o mapeamento dos espaços livres de edificação, públicos e privados, na cidade do Rio de Janeiro. A pesquisa referenciada considerou a incidência de espaços livres privados quadra a quadra, determinando dessa maneira o percentual de espaços livres existente na superfície das quadras:

- Espaços Livres Privados com incidência de até $30 \%$ na quadra urbana;

- Espaços Livres Privados com incidência acima de $30 \%$ até $50 \%$ na quadra urbana;

- Espaços Livres Privados com incidência acima $50 \%$ na quadra urbana.

Para os públicos, foram considerados todos os espaços livres de edificação das propriedades dos entes públicos, independentemente da existência ou não de restrição de acesso. Para a pesquisa em questão os espaços públicos foram segmentados de acordo com as definições de uso de propriedades públicas especificadas no Código Civil Brasileiro, vigente desde 2003:

- Espaços Livres Públicos de Uso Comum do Povo: são espaços de propriedade e apropriação pública, eventualmente pedagiados, ou que podem ser usados livre e gratuitamente. Também podem ser passíveis de alteração de uso, passando a serem bens de uso especial. São exemplos dessa categoria de espaços públicos as ruas, calçadas, praças, parques e orlas;

- Espaços Livres Públicos de Uso Especial: são aqueles destinados a atividades específicas e ao estabelecimento da administração pública, sendo utilizados no desempenho das atividades estatais. Citam-se como exemplo as áreas militares, os espaços livres nas faixas de domínio dos sistemas ferroviários, portuários e aeroportuários; espaços relacionados às infraestruturas urbanas como estações de tratamento de água e esgoto.

Com base na classificação acima, a arborização urbana foi então segmentada em seis principais categorias de análise:

1. Pública de circulação (de uso comum do povo UCP): arborização existente em espaços livres de uso comum do povo e de circulação como, por exemplo, ruas, avenidas, calçadas, canteiros, etc.;

2. Pública de permanência (de uso comum do povo - UCP): arborização existente em espaços livres de uso comum do povo e de permanência como, por exemplo, praças, parques, orlas de praia, etc.;

3. Pública especial (de uso especial - EU): arborização existente em espaços livres de uso especial, como, por exemplo, áreas militares, espaços de domínio portuário, aeroportuário, ferroviário, etc.;
4. Privada_30: arborização existente em espaços livres privadas localizadas em quadras urbanas com baixa incidência de espaços livres (até $30 \%$ );

5. Privada_30_50: arborização existente em espaços livres privadas localizadas em quadras urbanas com moderada incidência de espaços livres (entre $30 \%$ e $50 \%)$;

6. Privada_50: arborização existente em espaços livres privadas localizadas em quadras urbanas com elevada incidência de espaços livres (acima $50 \%)$.

\section{RESULTADOS}

Como resultado final, foram identificados 5.238 polígonos que representam, em sua totalidade, aproximadamente 616,67 hectares de arborização incidente na AP1 (Fig.4).

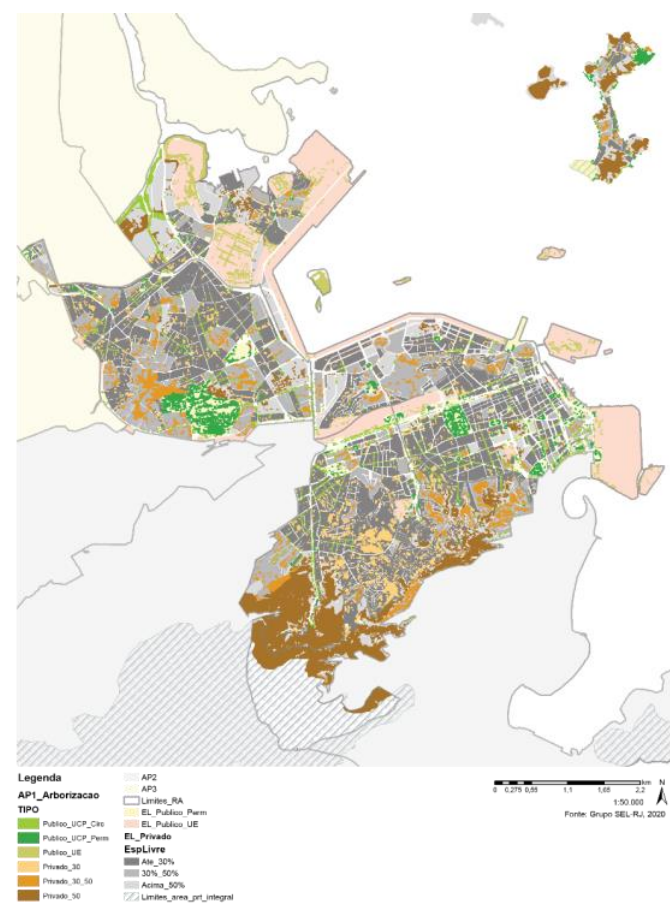

Figura 4: Arborização incidente nos espaços livres da AP1

Em linhas gerais, destaca-se o predomínio da arborização incidente em espaços livres privados, que representa mais de $70 \%(440,5$ hectares) de toda a massa arbórea identificada na AP1. Já a arborização incidente em espaços livres públicos representa $29 \%$ do total mapeado $(176,17$ hectares).

Em uma análise comparativa da incidência de arborização por Região Administrativa (Fig. 5), destacam-se como RAs mais arborizadas a RA III - Rio Comprido (26.4\%) e RA XXIII - Santa Teresa (24\%). Essas duas regiões são caracterizadas pelo uso essencialmente residencial, em quadras urbanas com elevada incidência de espaços livres (acima de $50 \%$ da área total da quadra). Um dos fatores pode explicar essa elevada incidência de espaços livres e arborização é o relevo. Ambas as RAs situam-se em 
área de acentuado declive e de altas cotas onde a ocupação é restrita (non-aedificandi) através da legislação vigente.

Já a RA II - Centro apresenta o menor percentual de arborização e, em contrapartida, a maior densidade edificada por quadra urbana, dentre as RAs da AP1. Sua ocupação é caracterizada, em sua grande maioria, por ter processos de ocupação mais antigos e por abranger uso comercial, através da implantação em lote, de grandes torres de escritórios. Essa característica, por consequência, é responsável pela baixa incidência de arborização nos lotes privados, onde a arborização pública (bem menos representativa do que a privada) representa aproximadamente $78 \%$ de toda massa arbórea dessa RA.

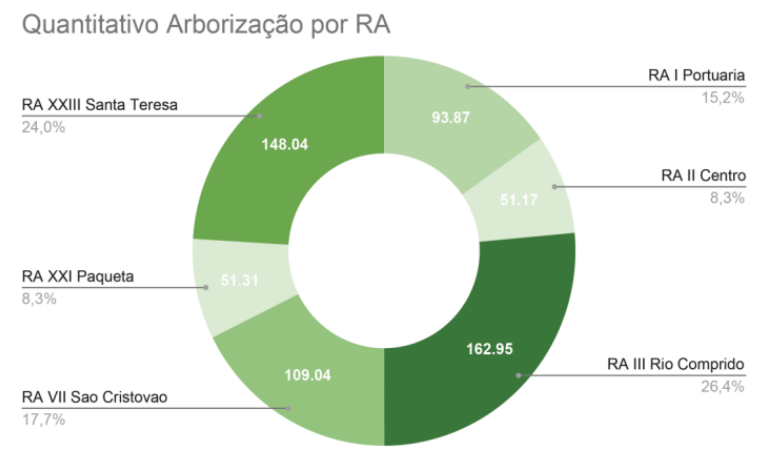

Figura 5: Arborização por Área de Planejamento (AP1)

Na análise individualizada da arborização pública (Fig. 6), a RA I - Portuária (32,5\%) e RA VII - São Cristóvão $(28,3 \%)$ se destacam sendo as regiões que concentram os maiores índices de arborização incidente nos espaços públicos. No primeiro caso, extensas áreas de uso dominial, representadas por faixas de domínio ferroviário, portuário e aeroportuário concentram expressiva área de massa arbórea. Já no caso da RA VII - São Cristóvão, a extensa área vegetada do Parque Municipal da Quinta da Boa Vista, antiga residência oficial da família imperial no Brasil, representa a maior área arborizada incidente em um único espaço público de permanência na AP1.

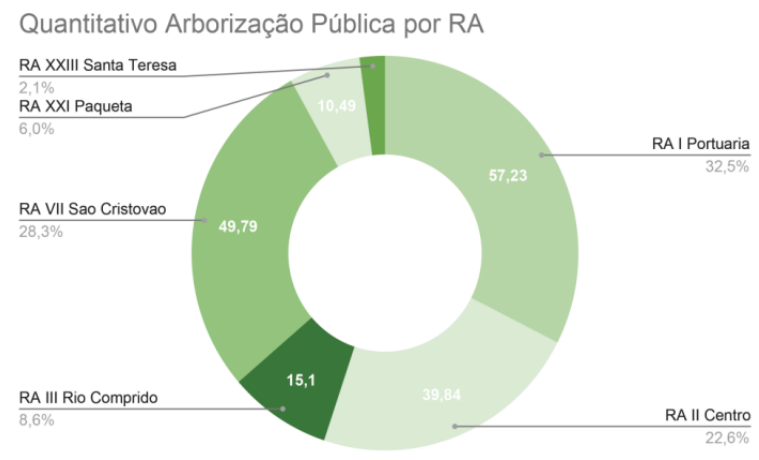

Figura 6: Arborização pública por Área de Planejamento (AP1).

De maneira sintetizada, os gráficos a seguir (Fig. 7 e Fig. 8) apresentam a distribuição da arborização em cada Região Administrativa da AP1, conforme as categorias de análise pré-definidas.

Com base nos resultados extraídos, é possível observar uma considerável superfície de espaços livres privados que conservam percentuais significativos de arborização. É o caso da RA III - Rio Comprido, RA XXI - Paquetá e RA XXIII - Santa Teresa. Já na RA I - Portuária, a baixa incidência de arborização em espaços públicos de permanência evidencia uma fragilidade da região: o reduzido número de espaços públicos destinados ao lazer, como praças e parques. Em contrapartida, destaca-se a importância dos espaços de uso especial para a manutenção da arborização pública, onde estão localizadas aproximadamente $63 \%$ de toda área pública vegetada da RA.

Na RA II - Centro constata-se a reduzida incidência de espaços livres privados intra-quadras e por consequência a baixa incidência de arborização presente nesses espaços. Já a elevada incidência de arborização em espaços públicos tanto de permanência como de circulação atenua de certa forma a deficiência arbórea existente no tecido urbano privado.

Por fim, na análise da distribuição de arborização da RA VII - São Cristóvão destaca-se o considerável percentual de arborização em quadras com moderada incidência de espaços livres e a arborização incidente em espaços públicos de permanência.
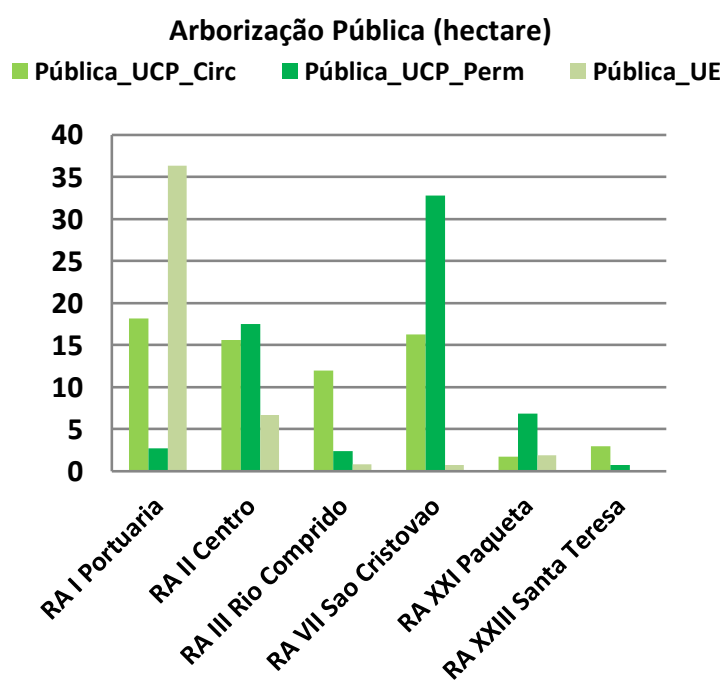

Figura 7: Arborização pública - Categorias de análise por $R A$. 


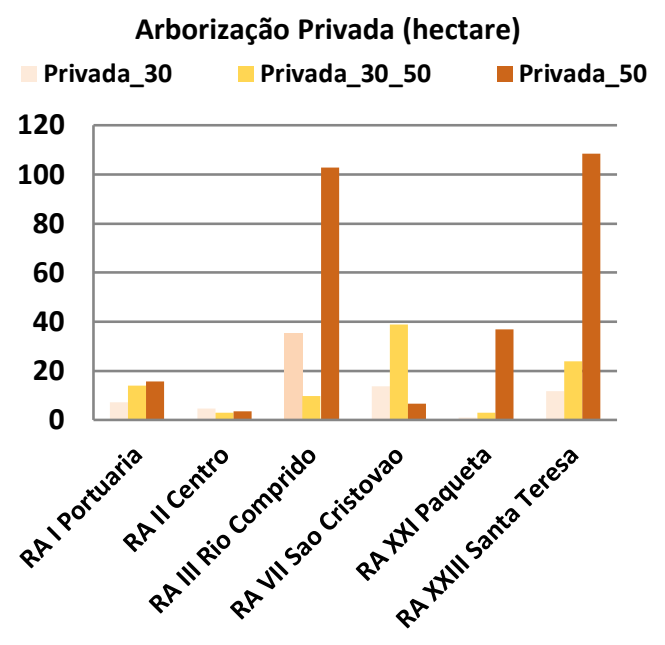

Figura 8: Arborização privada - Categorias de análise por $R A$.

\section{CONCLUSÃO}

O mapeamento da arborização na Cidade do Rio de Janeiro realizado nesse estudo evidencia a importância dos espaços privados para a manutenção de fragmentos de arborização urbana, principalmente em determinadas áreas de planejamento analisadas. Apesar de dimensões por vezes reduzidas, esses espaços contribuem de maneira compensatória na preservação de tais fragmentos de macha arbórea, que são por vezes inexistentes ou insuficientes em espaços livres públicos. Nesse contexto, os espaços livres privados, são, portanto, uma alternativa de espaços permeáveis capazes de contribuir para a melhoria das condições sociais e ambientais e um importante patrimônio a ser preservado.

O estudo realizado pode ainda ser importante instrumento na avaliação individualizada de cada Região Administrativa. A partir de análises comparativas e correlacionadas a outros temas (como é o caso dos espaços livres de edificação), a abordagem proposta nesse artigo pode auxiliar de forma significativa a elaboração de políticas públicas voltadas para o planejamento, implantação e monitoramento da arborização urbana, levando em consideração as diferentes formas das interações da arborização com a infraestrutura urbana, e os conflitos existentes em cada região da Cidade.

Em climas com características de temperatura e umidade como os da Cidade do Rio de Janeiro a incidência de arborização se constitui em demanda de conforto e bem estar, justificando a ampliação de estudos como os demonstrados no artigo para as demais áreas da cidade do Rio de Janeiro.

\section{REFERÊNCIAS}

1. BARRA, Eduardo; TÂNGARI, Vera Regina; SCHLEE, Mônica Bahia; BATISTA, Márcia Nogueira (ed.). (2015). A vegetação nativa no planejamento e no projeto paisagístico. Rio de Janeiro: RioBooks.

2. COLLINS, G; COLLINS, Christiane C. Camillo Sitte (2006). The Birth of Modern City Planning: With a Translation of the 1889 Austrian Edition of His City Planning According to Artistic Principles. Mineola, New York: Dover Publications.

3. CRUZ, B. M. (2013). Procedimentos metodológicos para avaliação da arborização urbana na cidade de São Paulo. Paisagem e Ambiente, (31), 25-60.

4. CULLEN, Gordon (1999). The concise townscape. Oxford: Architectural Press.

5. FARAH. I. (1997). Arborização Pública e Desenho Urbano na Cidade do Rio de Janeiro: A Contribuição de Roberto Burle Marx. (Tese de mestrado) - Rio de Janeiro: UFRJ/PROURB-FAU.

6. QUEIROGA, E. F; BENFATTI, D. M. (2007) Sistemas de espaços livres urbanos: construindo um referencial teórico. Revista Paisagem e Ambiente - Ensaios. São Paulo: FAUUSP, n. 24, p. 81-87.

7. LYNCH Kevin (1972). The image of the city. Boston: Cambridge Mass. M.I.T.

8. MAGNOLI, Miranda M. a. (2006). Espaço Livre objeto de trabalho. In: Revista Paisagem e Ambiente Ensaios, n. 21, p.175-197.

9. MAGNOLI, Miranda M. b. Em busca de "outros" espaços livres de edificação. In: Revista Paisagem e Ambiente - Ensaios, n. 21, p.142-174.

10. TÂNGARI, Vera R. (1999). Um outro lado do Rio. (Tese de doutorado). São Paulo: FAUUSP.

11. TANGARI, Vera R; SCHLEE, Mônica Bahia; ANDRADE, Rubens de. (org.) (2009). Sistema de espaços livres: o cotidiano, ausências e apropriações. Rio de Janeiro: FAU/UFRJ-PROARQ.

12. TÂNGARI, Vera R. (2018). Open Space Systems in Rio de Janeiro: The Public and Private Spheres Reflected in the Urban Landscape. In: Urban Public Spaces: From Planned Policies to Everyday Politics. Londres: Springer Nature, p. 1-15.

13. TANGARI, Vera R. (2019). Sistemas espaciais abertos no Rio de Janeiro: as esferas pública e privada refletidas na paisagem urbana In: Espaços públicos urbanos: das políticas planejadas à política cotidiana. Rio de Janeiro: Letra Capital, p. 140-160. 